\title{
EXPERIMENTAL INFECTION OF PONIES WITH SARCOCYSTIS FAYERI AND DIFFERENTIATION FROM SARCOCYSTIS NEURONA INFECTIONS IN HORSES
}

\author{
Author(s): W. J A. Saville, J. P. Dubey, M. J. Oglesbee, C. D. Sofaly, A. E. Marsh , E. Elitsur, M. C.
} Vianna, D. S. Lindsay, and S. M. Reed

Source: Journal of Parasitology, 90(6):1487-1491. 2004.

Published By: American Society of Parasitologists

DOI: http://dx.doi.org/10.1645/GE-313

URL: http://www.bioone.org/doi/full/10.1645/GE-313

BioOne (www.bioone.org) is a nonprofit, online aggregation of core research in the biological, ecological, and environmental sciences. BioOne provides a sustainable online platform for over 170 journals and books published by nonprofit societies, associations, museums, institutions, and presses.

Your use of this PDF, the BioOne Web site, and all posted and associated content indicates your acceptance of BioOne's Terms of Use, available at www.bioone.org/page/terms_of_use.

Usage of BioOne content is strictly limited to personal, educational, and non-commercial use. Commercial inquiries or rights and permissions requests should be directed to the individual publisher as copyright holder. 


\title{
EXPERIMENTAL INFECTION OF PONIES WITH SARCOCYSTIS FAYERI AND DIFFERENTIATION FROM SARCOCYSTIS NEURONA INFECTIONS IN HORSES
}

\author{
W. J. A. Saville, J. P. Dubey ${ }^{\star}$, M. J. Oglesbee†, C. D. Sofaly, A. E. Marsh, E. Elitsur, M. C. Vianna ${ }^{\star}$ D. S. Lindsay $\ddagger$, and \\ S. M. Reed $\S$ \\ Department of Veterinary Preventive Medicine, College of Veterinary Medicine, Ohio State University, Columbus, Ohio 43210-1092. e-mail: \\ saville.4@osu.edu
}

\begin{abstract}
Sarcocystis neurona and Sarcocystis fayeri infections are common in horses in the Americas. Their antemortem diagnosis is important because the former causes a neurological disorder in horses, whereas the latter is considered nonpathogenic. There is a concern that equine antibodies to $S$. fayeri might react with $S$. neurona antigens in diagnostic tests. In this study, 4 ponies without demonstrable serum antibodies to $S$. neurona by Western immunoblot were used. Three ponies were fed $1 \times 10^{5}$ to $1 \times 10^{7}$ sporocysts of $S$. fayeri obtained from dogs that were fed naturally infected horse muscles. All ponies remained asymptomatic until the termination of the experiment, day 79 postinoculation (PI). All serum samples collected were negative for antibodies to $S$. neurona using the Western blot at the initial screening, just before inoculation with $S$. fayeri (day 2 ) and weekly until day 79 PI. Cerebrospinal fluid samples from each pony were negative for $S$. neurona antibodies. Using the $S$. neurona agglutination test, antibodies to $S$. neurona were not detected in 1:25 dilution of sera from any samples, except that from pony no. 4 on day 28; this pony had received $1 \times 10^{7}$ sporocysts. Using indirect immunofluorescence antibody tests (IFATs), 7 serum samples were found to be positive for S. neurona antibodies from 1:25 to 1:400 dilutions. Sarcocystis fayeri sarcocysts were found in striated muscles of all inoculated ponies, with heaviest infections in the tongue. All sarcocysts examined histologically appeared to contain only microcytes. Ultrastructurally, S. fayeri sarcocysts could be differentiated from S. neurona sarcocysts by the microtubules (mt) in villar protrusions on sarcocyst walls; in $S$. fayeri the $\mathrm{mt}$ extended from the villar tips to the pellicle of zoites, whereas in $S$. neurona the $\mathrm{mt}$ were restricted to the middle of the cyst wall. Results indicate that horses with $S$. fayeri infections may be misdiagnosed as being $S$. neurona infected using IFAT, and further research is needed on the serologic diagnosis of $S$. neurona infections.
\end{abstract}

Horses in North America are infected with 2 Sarcocystis species, i.e., Sarcocystis fayeri and Sarcocystis neurona. Sarcocystis fayeri infections occur in approximately $30 \%$ of horses based on early research (Dubey et al., 1977), whereas approximately $50 \%$ of horses are exposed to S. neurona (Bentz et al., 1997; Blythe et al., 1997; Saville et al., 1997; Dubey, Lindsay, Saville et al., 2001).

Horses with $S$. fayeri infections may exhibit no clinical sign, or they may have mild to severe chronic illness with anemia, muscle soreness, and malnourishment (Tinling et al., 1980; Fayer and Dubey, 1982; Cawthorn et al., 1990). In contrast, equine protozoal myeloencephalitis, caused by $S$. neurona infections, is 1 of the most important and severe neurologic diseases affecting horses (Dubey, Lindsay, Saville et al., 2001). This becomes problematic because of the confusion in diagnosing either disease. Originally, a Western blot analysis was developed to detect antibodies to $S$. neurona in horses, which was reported to be able to differentiate between $S$. neurona and $S$. fayeri (Granstrom et al., 1993). Recently, another group of scientists reported that the Western blot analysis for $S$. neurona antibodies did not perform as well as an indirect immunofluorescence antibody test (IFAT) (Duarte et al., 2003).

The purpose of this study was to infect horses with $S$. fayeri

Received 13 January 2004; revised 26 March 2004; accepted 26 March 2004.

* Animal Parasitic Diseases Laboratory, Animal and Natural Resources Institute, U.S. Department of Agriculture, Agricultural Research Service, Beltsville, Maryland 20705-2350.

$\dagger$ Department of Veterinary Biosciences, College of Veterinary Medicine, Ohio State University, Columbus, Ohio 43210-1092.

† Department of Biomedical Sciences and Pathobiology, Center for Molecular Medicine and Infectious Disease, Virginia-Maryland Regional College of Veterinary Medicine, Virginia Tech, 1410 Prices Fork Road, Blacksburg, Virginia 40061-1092.

$\S$ Department of Large Animal Medicine, College of Veterinary Medicine, Ohio State University, Columbus, Ohio 43210-1092. sporocysts and follow them over time to demonstrate the ability to differentiate these infections from $S$. neurona infections.

\section{MATERIALS AND METHODS}

\section{Collection of Sarcocystis fayeri sporocysts and preparation of} horse inoculum

Muscles were collected from 20 horses from a slaughterhouse in Texas, and about $2 \mathrm{~kg}$ was fed to 3 laboratory-raised dogs. The dogs were killed 12 days later, and the sporocysts were collected from intestinal scrapings suspended in antibiotics, as described previously (Dubey et al., 1989). Sporocysts were counted using a hemacytometer and suspended in a concentration of $1 \times 10^{6}$ sporocysts $/ \mathrm{ml}$. Sporocyst inocula were shipped from Beltsville, Maryland, to the Ohio State University (OSU), Columbus, Ohio, for inoculation of the horses. Sporocysts had been stored for 163 days at $4 \mathrm{C}$ before being fed to ponies.

\section{Experimental infection of horses}

Four pony or pony-crossed weanling foals between 4 and 5 mo of age were purchased from a local horse dealer after testing negative for antibodies to $S$. neurona using Western blot analysis (Granstrom et al., 1993). All 4 ponies were males that ranged in weight from 55 to 97 $\mathrm{kg}$. The ponies were housed in the large-animal facility in the University Laboratory Animal Resource Center at the College of Veterinary Medicine, OSU. The control pony (no. 2) was housed in a separate stall. All ponies were fed heat-treated pellets (Buckeye Feeds, Dalton, Ohio) and autoclaved hay, as well as water, ad libitum.

All 4 ponies were randomly assigned to a treatment and subjected to complete physical examination on the day of arrival (day 0). Blood was collected from all ponies using vacutainer serum separator tubes. Each pony was sedated with xylazine (Sedazine ${ }^{\circledR}$, Fort Dodge Animal Health, Fort Dodge, Iowa) and Torbugesic ${ }^{\circledR}$ (Fort Dodge Animal Health) for cerebrospinal fluid (CSF) collection by standing lumbosacral puncture as described previously (Green et al., 1992). Aliquots of serum and CSF were submitted to a commercial laboratory (Equine Biodiagnostics, Inc., Lexington, Kentucky) for Western blot analysis to detect antibodies to $S$. neurona. After CSF collection, ponies nos. 1, 3, and 4 were administered assigned 100,000, $1 \times 10^{6}$, and $1 \times 10^{7} \mathrm{~S}$. fayeri sporocysts, respectively, by nasogastric intubation. Pony no. 2 was administered an equal volume of normal saline as a placebo.

The ponies were observed daily for general health (temperature, pulse, and respiratory rate) and appetite. Serum samples were collected weekly for detection of $S$. neurona antibodies. Just $24 \mathrm{hr}$ before being 
TABLE I. Detection of antibodies to Sarcocystis neurona in sera of ponies fed $S$. fayeri sporocysts.

\begin{tabular}{|c|c|c|c|c|c|}
\hline \multirow{2}{*}{$\begin{array}{c}\text { Pony } \\
\text { no. }\end{array}$} & \multirow[b]{2}{*}{ Dose } & \multirow[b]{2}{*}{ Day PI } & \multicolumn{3}{|c|}{ S. neurona antibodies } \\
\hline & & & Immunoblot* & $\mathrm{SAT} \dagger$ & IFAT \\
\hline \multirow[t]{3}{*}{1} & $10^{5}$ & 2 & Negative & $<25$ & $<25$ \\
\hline & & 37 & Negative & $<25$ & 25 \\
\hline & & 79 & Negative & $<25$ & 100 \\
\hline \multirow[t]{3}{*}{2} & None & 2 & Negative & $<25$ & $<25$ \\
\hline & & 37 & Negative & $<25$ & $<25$ \\
\hline & & 79 & Negative & $<25$ & 25 \\
\hline \multirow[t]{3}{*}{3} & $10^{6}$ & 2 & Negative & $<25$ & $<25$ \\
\hline & & 37 & Negative & $<25$ & 400 \\
\hline & & 79 & Negative & $<25$ & 100 \\
\hline \multirow[t]{3}{*}{4} & $10^{7}$ & 2 & Negative & $<25$ & $<25$ \\
\hline & & 37 & Negative & $1: 50 \dagger$ & 100 \\
\hline & & 79 & Negative & $<25$ & 100 \\
\hline
\end{tabular}

* Western blot by Equine Biodiagnostics, Inc. (Granstrom et al., 1993); no reaction.

$\dagger$ Sarcocystis neurona agglutination test (Lindsay and Dubey, 2001)

† Indirect immunofluorescence antibody test (Duarte et al., 2003).

killed, serum and CSF samples of all ponies were collected. After death with Beuthanasia ${ }^{\circledR}$-D (Schering-Plough, Union, New Jersey), a complete postmortem examination was performed on all ponies except the control pony. The control pony was donated to 1 of the authors.

\section{Postmortem examination of experimental horses}

During postmortem examination, samples of bladder, spleen, pancreas, kidney, liver, adrenal, heart, lung, diaphragm, quadriceps muscles, and tongue were fixed in $10 \%$ buffered neutral formalin and processed for routine examination of hematoxylin and eosin-stained sections after paraffin embedding. Retrospectively, formalin-fixed pieces of tongue from pony no. 4 were prepared for transmission electron microscopy (TEM) as described previously (Stanek et al., 2002).

\section{Immunohistochemical examination}

Paraffin-embedded sections of tongue from all 3 ponies fed $S$. fayeri were reacted with $S$. neurona antibodies in an immunohistochemical test (Stanek et al., 2002).

\section{Serological examination for antibodies to Sarcocystis neurona}

Antibodies to $S$. neurona were assessed in sera of ponies by Western immunoblot, S. neurona agglutination test (SAT), and IFAT. The immunoblots were performed at Equine Biodiagnostics, Inc., as described by Granstrom et al. (1993). SAT was performed at Virginia Tech, Blacksburg, Virginia, as described by Lindsay and Dubey (2001), and all 12 weekly samples from each pony were examined. Samples examined for SAT were initially screened at 1:25 dilution, and positive samples were titrated. IFAT was performed at the University of California Veterinary Teaching Hospital, Davis, California, as described by Duarte et al. (2003). For IFAT, 3 serum samples from each pony (days 2,37 , and 79 of the experiment) were examined using 1:25, 1:100, and 1:400 dilutions on each serum. SAT and IFAT were performed blindly without knowing the pony number or whether they were treated ponies or controls.

\section{RESULTS}

\section{Experimental horse results}

All serum samples collected were negative for antibodies to $S$. neurona using Western blot at initial screening, just before inoculation with $S$. fayeri (day 2) and weekly until day 79 postinoculation (PI). Both CSF samples collected on day 2 and day 82 PI from each pony were negative for $S$. neurona antibodies. Antibodies to $S$. neurona were not detected in 1:25 dilution of sera from any sample except in 1 case. The exception was the sample collected from pony no. 4 on day 28 that was positive at 1:50 dilution. Results of IFAT are given in Table I.

Sarcocysts were found in striated muscles of all inoculated ponies. Tongue contained the most numbers of sarcocysts (Fig. 1). In histologic sections, sarcocysts were up to $40 \mu \mathrm{m}$ wide and up to $1,000 \mu \mathrm{m}$ long. All sarcocysts examined histologically appeared to contain only metrocytes and no bradyzoites (Figs. 1, 2). The sarcocyst wall was up to $4 \mu \mathrm{m}$ wide (Fig. 1A), and sarcocysts with cyst wall of different widths were found in the same section (Fig. 1A). By light microscopy, the cyst wall was found to be striated. Sarcocysts from all 3 ponies did not stain with $S$. neurona antibodies.

Ultrastructurally, the sarcocyst wall consisted of villar pro-

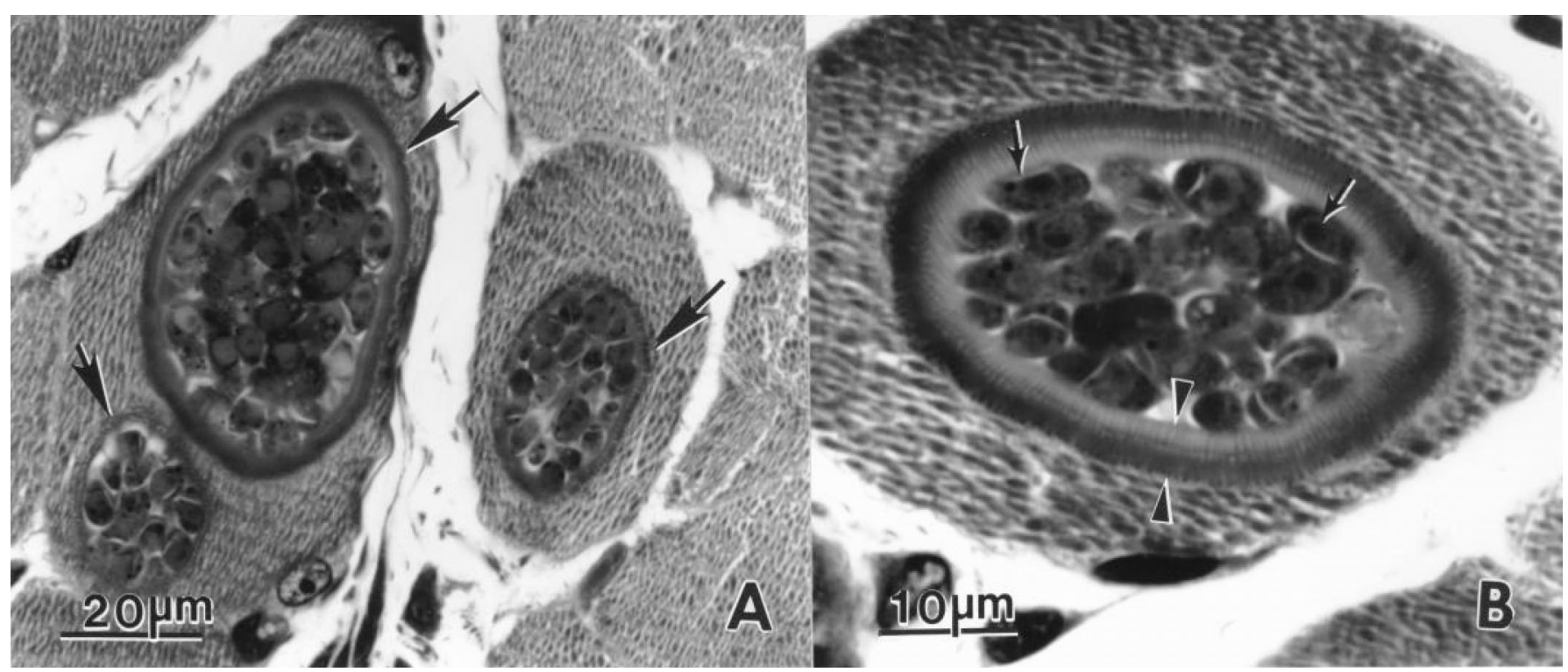

Figure 1. Sections of sarcocysts of Sarcocystis fayeri in tongue of pony no. 4. Toluidine blue stain. (A) Three sarcocysts with varying thickness of the cyst wall (arrows). (B) Sarcocyst with thick cyst wall (arrowheads) and metrocysts (arrows). 


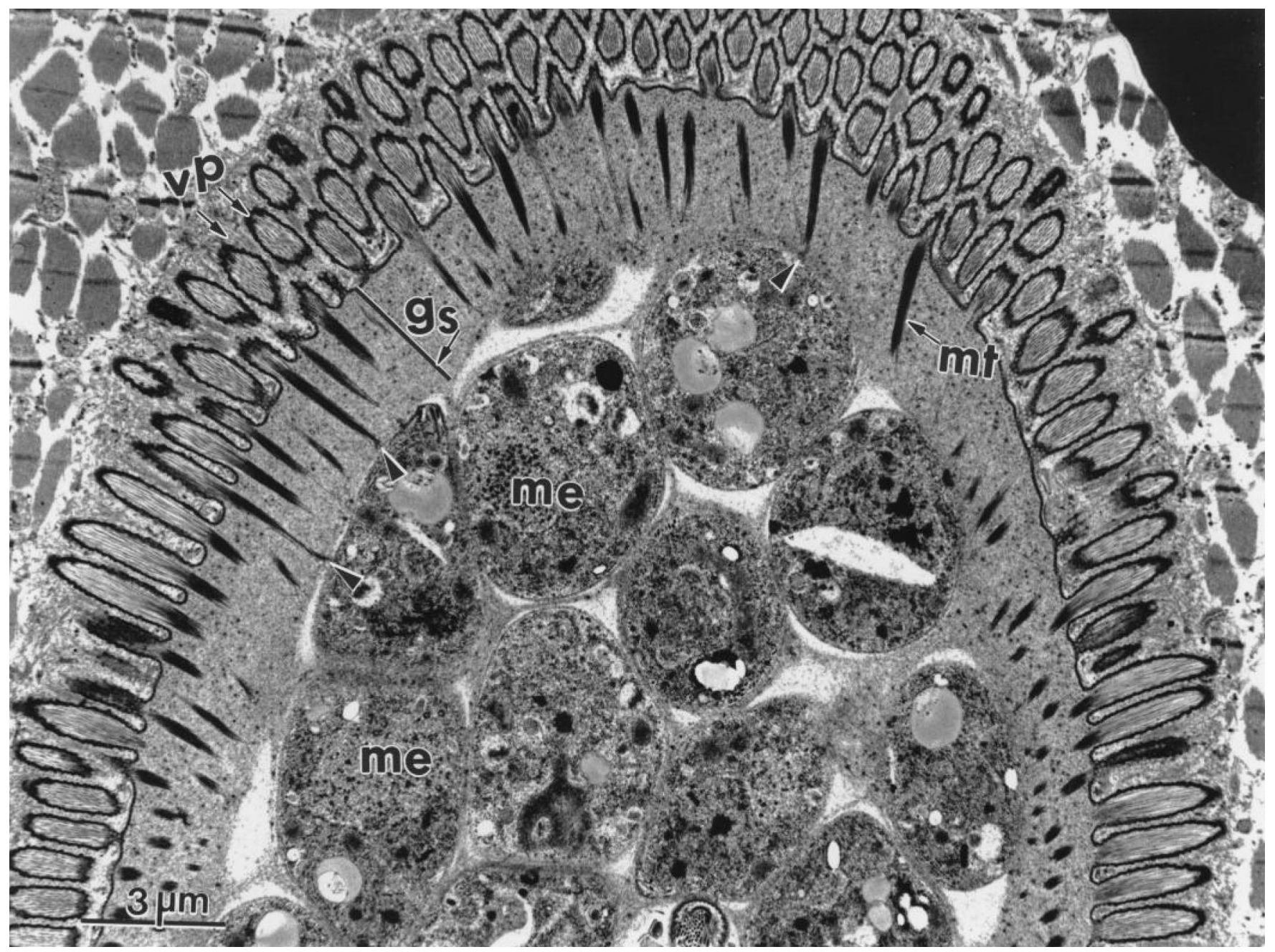

FIGURE 2. Transmission electron micrograph of a sarcocyst of Sarcocystis fayeri. Note elongated villar protrusions (vp), with microtubules (mt) that extend into the ground substance (gs) up to the pellicle of metrocytes (me) (arrowheads). Only me and no bradyzoite was seen in this cyst.

trusions (vp) and the ground substance (gs) layer. The parasitophorous vacuolar membrane (pvm), the outermost membrane covering vp, was embedded into the host cell cytoplasm (Figs. 2, 3). The pvm was lined by an electron-dense layer (edl), which varied in density and width. The edl was thickest and most dense at the tip than at the base of the vp (Fig. 3). Porelike structures were formed by the thinness of the edl at the base of the vp. The edl was up to $90 \mathrm{~nm}$ thick at the tip of the vp.

Each vp contained prominent microtubules (mt) that extended from the tip to the base and even up to the pellicle of metrocytes. The structure of the $\mathrm{mt}$ varied depending on the location in the sarcocyst. Mt in the vp had no visible electrondense granule. The $\mathrm{mt}$ were unevenly spaced in the vp. Mt in the gs layer were tightly packed and converged toward the pellicle of the metrocytes. They were remarkably more electron dense in the gs layer than in the vp. The gs layer was up to 2.5 $\mu \mathrm{m}$ wide and relatively devoid of electron-dense structures, except for the presence of $\mathrm{mt}$.

The metrocytes were approximately $8 \times 5 \mu \mathrm{m}$ in size. No bradyzoite was observed using TEM.

\section{DISCUSSION}

This study demonstrates that we are able to distinguish $S$. fayeri from $S$. neurona infections in horses after experimental infection with $S$. fayeri sporocysts. This can be accomplished using the Western blot analysis as described by Granstrom et al. (1993). There appears to be some cross-reactivity using both SAT and IFAT in some instances.

SAT was positive in only 1 instance, on day $37 \mathrm{PI}$, at 1:50 dilution; however, this horse received the highest dose $(1 \times$ $10^{7}$ ) of sporocysts. On the other hand, IFAT was positive at 1: 100 in all 3 inoculated ponies and 1:400 in 1 pony. Duarte et al. (2003) considered a titer of 1:80 as a specific IFAT titer for $S$. neurona based on data from naturally infected horses. Further research is needed to assess whether the severity of $S$. fayeri infection affects the cross-reactivity to $S$. neurona.

The ultrastructure of $S$. fayeri sarcocysts in this study is remarkably similar to that of $S$. fayeri-like sarcocysts in a naturally infected horse from California described in detail by Tinling et al. (1980), with 1 exception. Tinling et al. (1980) reported 


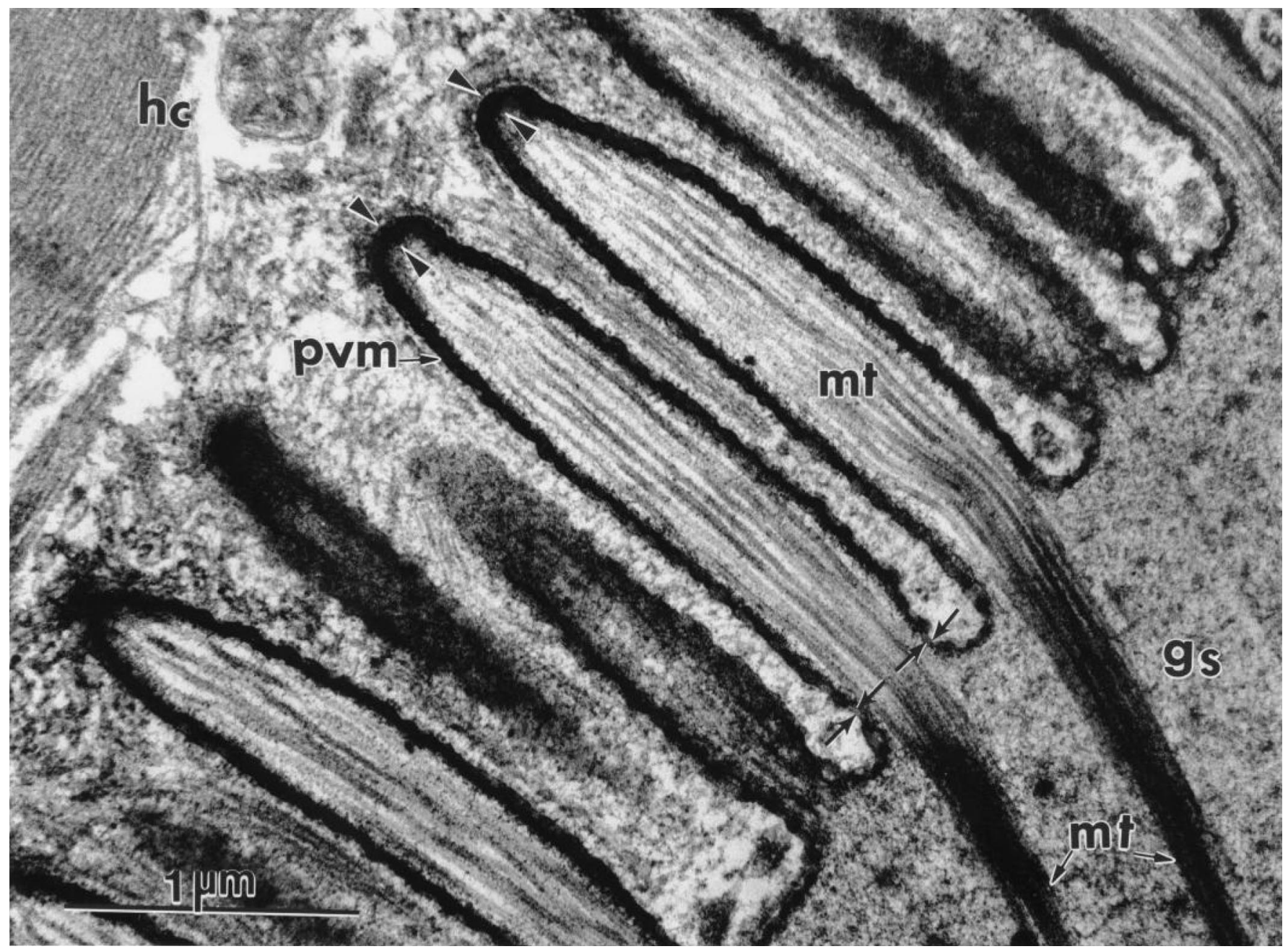

FIGURE 3. Transmission electron micrograph of a sarcocyst of Sarcocystis fayeri. Note details of the villar protrusions (vp) extending into the host cell (hc). The parasitophorous vacuolar membrane (pvm) is lined by an electron-dense layer that is thicker at the villar tips (arrowheads) and narrow at the base of the vp (arrowheads). Microtubules (mt) extend from the tip to the base of the vp into the ground substance (gs), and they are more electron dense in the gs than in the vp.

linearly arranged electron-dense structures in mt. These bodies were not seen in this study. Cawthorn et al. (1990) also found these electron-dense structures in another naturally infected horse from Canada. Specimens in this study were fixed in formalin, whereas Tinling et al. (1980) and Cawthorn et al. (1990) fixed specimens in glutaraldehyde. Whether these procedures used or the stage of the maturity of sarcocysts examined made the difference is unknown. Sarcocysts in this study were immature, whereas in the other 2 studies they were mature. It was surprising to find only immature sarcocysts in this study in ponies killed 79 days PI. In our previous study, sarcocysts had matured in a pony killed 77 days PI (Fayer and Dubey, 1982).

In general, the sarcocysts of $S$. fayeri appeared similar to those of $S$. neurona in tissues of cats and raccoons fed $S$. neurona sporocysts from the feces of opossums (Dubey, Lindsay, Fritz et al., 2001; Stanek et al., 2002). However, there were differences in vp of these parasites. The villar tips of $S$. fayeri were stubby, whereas those in $S$. neurona were more pointed. Mt in the gs layer were not as electron dense in $S$. neurona as in $S$. fayeri. Although most sarcocysts were immature, sarco- cysts of $S$. fayeri did not react with antibodies to $S$. neurona. We are aware that staining of sarcocysts with antibodies raised against merozoites may vary. Immature sarcocysts of $S$. neurona reacted well with $S$. neurona antibodies, and this reactivity was diminished with the maturation of sarcocysts (Stanek et al., 2002). It is important to recognize these differences because $S$. neurona sarcocysts have not yet been documented in horses.

In conclusion, this study has demonstrated that infections with $S$. fayeri and S. neurona in horses can be distinguished using Western blot testing of sera for antibodies to $S$. neurona and that the sarcocysts of the 2 species are structurally different enough to distinguish them using microscopy. Because of its varied presentation and high seroprevalence, we are still faced with uncertainty in the diagnosis of clinical $S$. neurona infections. Consequently, much more research is necessary in this area to develop more specific testing modalities.

\section{LITERATURE CITED}

Bentz, B. G., D. Granstrom, And S. Stamper. 1997. Seroprevalence of antibodies to Sarcocystis neurona in horses residing in a county 
of southeastern Pennsylvania. Journal of the American Veterinary Medical Association 210: 517-518.

Blythe, L. L., D. E. Granstrom, D. E. Hansen, L. L. Walker, J. BARTLETT, AND S. STAMPER. 1997. Seroprevalence of antibodies to Sarcocystis neurona in horses residing in Oregon. Journal of the American Veterinary Medical Association 210: 525-527.

Cawthorn, R., M. Clark, R. Hudson, and D. Friessen. 1990. Histological and ultrastructural appearance of severe Sarcocystis fayeri infection in a malnourished horse. Journal of Veterinary Diagnostic Investigation 2: 342-345.

Duarte, P. C., B. M. Daft, P. A. Conrad, A. E. Packham, and I. A. GARDNER. 2003. Comparison of a serum indirect fluorescent antibody test with two Western blot tests for the diagnosis of equine protozoal myeloencephalitis. Journal of Veterinary Diagnostic Investigation 15: 8-13.

Dubey, J. P., D. S. Lindsay, W. J. A. Saville, S. M. Reed, D. E GRANSTROM, AND C. A. SPEer. 2001. A review of Sarcocystis neurona and equine protozoal myeloencephalitis (EPM). Veterinary Parasitology 95: 89-131.

- - D. Fritz, And C. A. Speer. 2001. Structure of Sarcocystis neurona sarcocysts. Journal of Parasitology 87: 13231327.

, C. A. SPEer, AND R. FAYER. 1989. Sarcocystosis of animals and man. CRC Press, Boca Raton, Florida, 215 p.

, R. H. Streitel, P. C. Stromberg, and M. J. Toussant. 1977. Sarcocystis fayeri sp. n. from the horse. Journal of Parasitology 63: 443-447.
FAyer, R., AND J. P. Dubey. 1982. Development of Sarcocystis fayeri in the equine. Journal of Parasitology 68: 856-860.

Granstrom, D. E., J. P. Dubey, S. W. Davis, R. Fayer, J. C. Fox, K. B. Poonacha, R. C. Giles, And P. F. Comer. 1993. Equine protozoal myeloencephalitis: Antigen analysis of cultured Sarcocystis neurona merozoites. Journal of Veterinary Diagnostic Investigation 5: $88-90$.

Green, E., G. M. Constantinescu, and R. A. Kroll. 1992. Equine cerebrospinal fluid: Physiologic principles and collection techniques. Compendium for Continuing Education of Practicing Veterinarians 14: 229-237.

Lindsay, D., AND J. P. Dubey. 2001. Direct agglutination test for the detection of antibodies to Sarcocystis neurona in experimentally infected animals. Veterinary Parasitology 95: 179-186.

Saville, W. J., S. M. Reed, D. E. Granstrom, K. W. Hinchcliff, C. W. Kohn, T. E. Wittum, and S. Stamper. 1997. Prevalence of serum antibodies to Sarcocystis neurona in horses residing in Ohio. Journal of the American Veterinary Medical Association 210: 519 524.

Stanek, J. F., J. P. Dubey, M. J. Oglesbee, S. M. Reed, D. S. Lindsay, C. J. NJoku, AND W. J. A. SAviLle. 2002. Life cycle of Sarcocystis neurona infections in its natural intermediate host, raccoon (Procyon lotor). Journal of Parasitology 88: 1151-1158.

Tinling, S. P., G. H. Cardinet, L. L. Blythe, M. Cohen, and S. L. VONDERFECHT. 1980. A light and electron microscopic study of sarcocysts in a horse. Journal of Parasitology 66: 458-465. 